\title{
Análise de um Caso de Extinção do Poder Familiar ${ }^{1}$
}

\author{
A Case Study Analysis on a Withdraw of Parents' Legal Authority
}

\section{Paula \\ Inez Cunha \\ Gomide}

Doutora em Psicologia

Experimental pela USP-

1990.

Professora do

Programa de Pós-

Graduação em

Psicologia da Infância

e Adolescência da

UFPR.

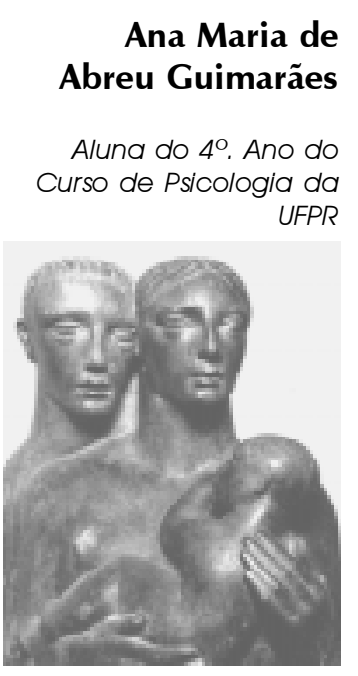

Patrícia Meyer

Aluna do $4^{\circ}$. Ano do Curso de Psicologia da

\begin{abstract}
Resumo: Este estudo procurou demonstrar os caminhos percorridos pelos pesquisadores para constituírem um processo de destituição do poder familiar a partir da análise cuidadosa da documentação de uma criança, abrigada por maus tratos, há três anos sem a visita dos pais. Foram realizadas observações e entrevistas com seus familiares para que um pleno convencimento sobre os devidos encaminhamentos fossem tomados. Ao final do estudo, o processo foi instaurado a pedido do próprio pai da criança que instituiu, inclusive, advogada para dar andamento ao caso. O poder familiar foi cassado e a criança colocada para adoção.
\end{abstract}

Palavras-chave: Família, Psicologia jurídica, adoção.

Abstract: This study aimed to reveal the pathway used by researchers to withdraw from careless parents their legal authority upon a child who was abandoned for three years in an institution. Many interviews were made with the child's relatives to discuss the convenience of beginning a legal process that would lead to the loss of their parental duties. In the end the father himself opened the case (through his attorney). The conclusion has not yet been taken and the process is still under judgment.

Key-words: Family, adoption.

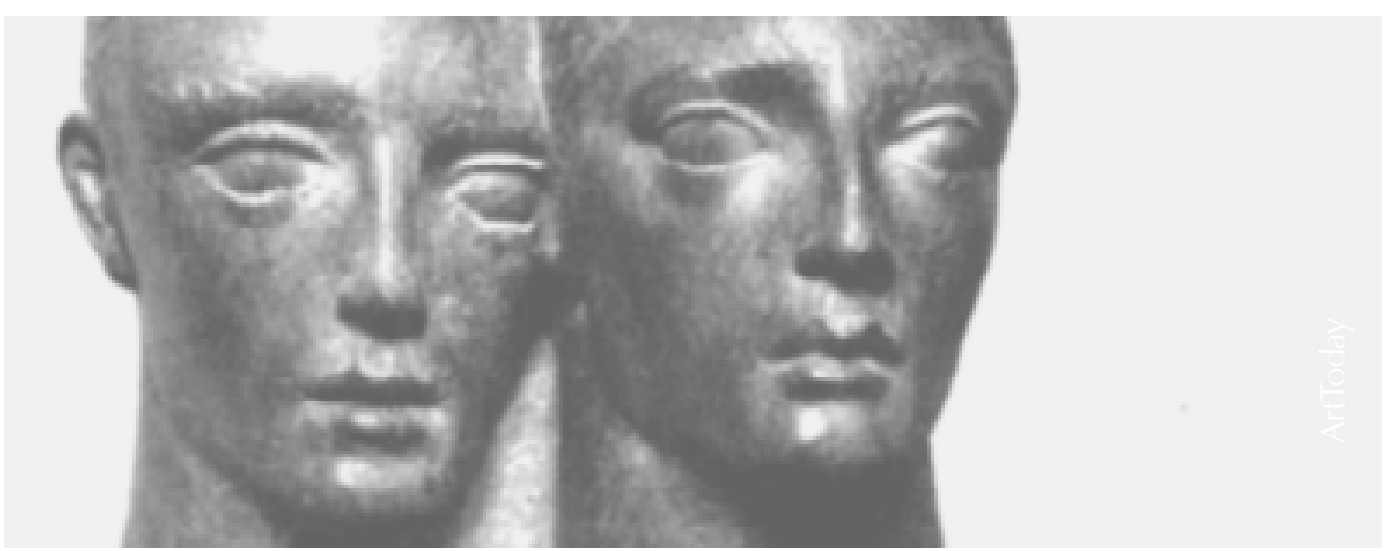

O Estatuto da Criança e do Adolescente trouxe uma nova perspectiva legal para o encaminhamento de crianças e adolescentes internados em instituições de abrigo. Anteriormente ao ECA, o Estado entendia que seu dever era tão somente abrigar essas crianças até sua maioridade. O ECA determina que as equipes técnicas desenvolvam programas de recolocação dos abrigados em suas famílias de origem ou favoreçam o seu encaminhamento a programas de adoção. No entanto, esses programas de atendimento considerados vitais para o pleno desenvolvimento das crianças abrigadas são ainda muito incipientes. Estudo de Weber e Kossobudzky (1976) identificou, em 1367, que dos abrigados em instituições paranaenses, apenas 8,49\% tinham o pátrio poder cassado, embora 41, $04 \%$ nunca tenham recebido visita dos pais.

\section{O Poder Familiar}

O Código Civil do início do século XX (1916) designava o marido como chefe da sociedade conjugal e este contava com a ajuda da mulher para o interesse comum do casal e dos filhos (art. 233, incisos I, II, III, IV e art. 234). A mulher assumia a condição de companheira, consorte e colaboradora (art 240 e seguintes). Com o advento do novo Código Civil de 2002, no art. 1565 observa-se a significativa diferença no texto jurídico ao afirmar que homens e mulheres assumem mutuamente a condição de consortes, companheiros e responsáveis pelos encargos da família, sendo a direção da sociedade conjugal exercida pelo homem e pela mulher, sempre no interesse do casal e dos filhos (art. 1567).

Houve o fim do pátrio poder. O poder do pai sobre os filhos passa a ser chamado de "poder familiar" - a ser exercido igualmente pelo pai e pela mãe. Da mesma forma, o homem deixa de ser o chefe da família, que agora é dirigida pelo casal, com iguais poderes.

No art. 1634, o novo Código Civil repete o que já era definido no antigo Código no que se refere às 
obrigações dos que detêm o poder familiar, ou seja: dirigir a criação e a educação dos filhos, tê-los em sua companhia e guarda, conceder-lhes ou negar-lhes consentimento para casarem, nomear-lhes tutor, por testamento ou documento autêntico, se o outro dos pais não lhe sobreviver ou não puder exercitar o poder familiar, representá-los até os 16 anos nos atos da vida civil e assisti-los, após essa idade, nos atos em que forem partes, suprindo-lhes o consentimento, reclamálos de quem ilegalmente os detenha e exigir que thes prestem obediência, respeito e os serviços próprios de sua idade e condição.

Esse artigo demonstra claramente que os pais ou aqueles que detenham a guarda da criança têm obrigações e responsabilidades para com a sua segurança, educação, bem-estar, enfim, todos os cuidados elencados na Constituição que fazem parte da filosofia do melhor interesse da criança.

O art. 1635 define as condições necessárias para a suspensão e extinção do poder familiar, ou seja, ele dar-se-á pela morte dos pais ou do filho, pela emancipação, nos termos do art. 5o, parágrafo único, pela maioridade, pela adoção ou por decisão judicial, na forma do art. 1638. O art. 1638 expressa que perderá por ato judicial o poder familiar o pai ou a mãe que castigar imoderadamente o filho, deixar o filho em abandono ou praticar atos contrários à moral e aos bons costumes.

A extinção do poder familiar é medida grave. Não é temporária, mas definitiva, o que não significa que os pais não poderão reaver seus direitos e deveres, porém será necessária prova muito significativa e forte para que essa ação judicial seja revertida.

O art. 227, do Capítulo VII da Constituição Federal, diz que "Caso impossível, absolutamente inviável ou não recomendável a permanência da criança e do adolescente em companhia de seus pais, após esgotadas as tentativas que nesse sentido deverão ser obrigatórias e ex vi legis realizadas, a colocação do jovem em família substituta surge como a melhor forma de superar a falta, o abuso ou a reiterada e injustificável omissão de sua família natural, garantindo àquele seu direito fundamental de ser criado e educado no seio de uma família, ainda que não seja a de origem (inteligência da terceira parte do citado art. 19 da Lei no 8.069/90)" (p.158).

O art. 5을 do ECA afirma que "nenhuma criança ou adolescente será objeto de qualquer forma de negligência, discriminação, exploração, violência, crueldade e opressão, punindo na forma da lei qualquer atentado, por ação ou omissão, aos seus direitos fundamentais". Pode-se verificar que os artigos são claros ao estabelecerem que maus-tratos e outros atos que prejudiquem a saúde física, psicológica e até financeira dos filhos devem ser objeto de intervenção judicial no interesse de proteção da criança. $\mathrm{O}$ art. 23 do ECA ressalta que a pobreza não é motivo para a destituição do pátrio poder. Ele é claro: "A falta ou carência de recursos materiais não constitui motivo suficiente à perda ou à suspensão do pátrio poder". As famílias nessas condições devem ser obrigatoriamente incluídas em programas oficiais de auxílio.

Todas as propostas políticas de atendimento a famílias de crianças abrigadas devem ter como prioridade absoluta a reaproximação da criança à sua família de origem. A extinção do poder familiar somente deve ocorrer caso fique evidente que não há possibilidade de a criança voltar à sua família, que esta não tem interesse em recebê-la de volta ou que o comprometimento das relações familiares por espancamento, uso de drogas ou abuso sexual demonstraram que o núcleo familiar está muito enfermo e que os prejuízos para a criança seriam enormes caso ela retornasse. Deve-se buscar, nesses casos, a concordância dos pais para a facilitação do processo de extinção do poder familiar.

O Brasil incorporou, em caráter definitivo, o princípio do "melhor interesse da criança" em seu sistema jurídico. Esse princípio tem representado um norteador importante para a modificação das legislações internas no que concerne à proteção da infância em nosso continente (Pereira, 2000). Atualmente, a aplicação do princípio do melhor interesse permanece como um padrão, considerando as necessidades da criança em detrimento de seus pais.

Segundo Barboza (2000), o Estatuto da Criança e do Adolescente concretizou e expressou os novos direitos da população infanto-juvenil, que põem em relevo o valor intrínseco da criança como ser humano e a necessidade de especial respeito à sua condição constitucional de pessoa em desenvolvimento. Essa autora afirma que a adoção, em sede constitucional, da doutrina da proteção integral, veio reafirmar o princípio do melhor interesse da criança, já existente em nossa legislação e que encontra suas raízes na Declaração Universal dos Direitos da Criança, adotada pela ONU em 20 de novembro de 1959. Prossegue ainda Barboza afirmando que o princípio do melhor interesse da criança, como orientador da solução dos conflitos envolvendo menores, já estava consagrado antes mesmo da Constituição Federal de 1988 pelo extinto Código de Menores (pág. 205).

Segundo Guimarães (1999), "Comprovado o estado de abandono em que se encontravam os infantes, bem como os atos contrários à moral e aos bons costumes praticados pela apelante na presença das menores, a destituição do pátrio poder é imperativo legal". Ainda segundo o Desembargador Guimarães, a inserção da criança institucionalizada no seio familiar, preservando os laços familiares, é o alvo primário. Entretanto, quando se observa a incapacidade de os genitores exercerem os direitos e deveres inerentes ao pátrio poder não se pode retardar a solução drástica consistente da cassação ou suspensão desse pátrio poder, sob pena de, ao se procurar proteger os direitos dos pais, causar dano irremediável à criança ou ao adolescente, retardando indevidamente o gozo do
1 As pesquisadoras agradecem a participação das alunas do curso de Psicologia da UFPR Flávia Bello e Vanessa Bilange Montenegro, que auxiliaram na fase de coleta de dados desta pesquisa. 
direito de ser criado e educado em família substituta, assegurando-lhe a convivência familiar e comunitária". Esse texto fez parte de um processo de destituição de pátrio poder de uma criança cuja mãe usava drogas na presença das filhas, se prostituía, deixava as filhas em estado de abandono, além de causar-lhes maus tratos. "Jovem mãe, dependente química, com vida totalmente desestruturada, com histórico de prostituição, abandono total, indiferença ao bem-estar da prole e ao seu próprio. Tem histórico de inúmeros comportamentos anti-sociais entre eles, uma tentativa de homicídio, sendo apreendida inúmeras vezes e constantemente; leva para seu domicílio seus distintos parceiros, bem como utiliza substâncias viciantes na presença das filhas". Ressalta-se, ainda, que o pai concordou com a destituição, pois não podia cuidar da filha que possuía oito anos e sabia que a mãe não tinha condições. Salienta também Guimarães que a mãe possui condições financeiras e que, portanto, esse não foi o motivo da destituição.

\section{Abandono e Adoção}

Embora a

legis/ação seja clara, afirmando que a pobreza não constitui motivo para a extinção do poder familiar, até

recentemente esse era o principal

determinante para o encaminhamento de crianças oriundas de famílias desassistidas para abrigos.
Segundo Gagno (2002) na cultura ocidental a adoção acha-se relacionada a abandono. A maioria dos casos de abandono acontece por motivo de pobreza, mas a causa também pode ser a morte dos pais, a decisão dos pais de abandonar os filhos ou a incapacidade dos pais em cuidar dos filhos.

Embora a legislação seja clara, afirmando que a pobreza não constitui motivo para a extinção do poder familiar, até recentemente esse era o principal determinante para o encaminhamento de crianças oriundas de famílias desassistidas para abrigos. $\mathrm{O}$ investimento em políticas públicas de apoio às famílias de risco social não está sendo feito. Ainda se verifica que os Conselhos de Direito da Criança e do Adolescente permanecem apoiando iniciativas voltadas para a manutenção de crianças em abrigos e casas-lares, apesar do discurso corrente de reintegração familiar e programas de assistência às famílias de risco. As famílias que abandonam seus filhos são certamente vítimas dos mesmos processos de abandono que agora perpetuam em sua prole. Foram também negligenciadas, abusadas física e psicologicamente, desassistidas pela família e pelo Estado.

A função de cuidador exercida pela mãe, segundo Bowlby (1984a, 1984b), cria vínculos afetivos que atendem as necessidades básicas afetivas e psicológicas da criança. Nessas condições, a criança desenvolve apego à figura materna (biológica ou adotiva). A figura de apego significa basicamente proteção para a criança. A separação e a perda da figura materna são fatores determinantes dos sentimentos de medo e angústia na criança. O autor observou que, após ausência prolongada da mãe, a criança apresentava-se aflita, com reações agressivas, de afastamento, de desconfiança e de desamparo. Concluiu que uma criança desprezada pelos pais acredita que é indesejada por todos e não apenas pelos pais; já uma criança amada pelos pais confia que seja digna de afeição por todos.

A negligência é uma forma de abandono na qual o cuidador está presente, porém não propicia à criança o afeto e os cuidados necessários. Ferrão (2000) define a negligência como um tipo de mau-trato por omissão e cita três tipos de negligência: a física (ausência de cuidados médicos, de alimentação, de vestuário, de monitoria que aumentem o risco de acidentes), a emocional (privação de afeto e suporte emocional) e educativa (privação da escolaridade básica, absentismo escolar e ausência de acompanhamento das atividades acadêmicas).

Supõe-se que o comportamento reativo agressivo seja promovido pelo comportamento parental em que há pobre apego no relacionamento por parte dos pais para com a criança, como por exemplo: falta de calor e carinho na interação com a criança, o que pode desencadear sentimentos de insegurança, vulnerabilidade e eventual hostilidade e agressão em relacionamentos sociais (Dodge, Pettit \& Battes, 1994). Assim, a experiência de carinho por parte dos pais no relacionamento com os filhos deve diminuir o risco de futuro desenvolvimento de violência nos relacionamentos íntimos de seus filhos.

Outro fator que poderá levar à extinção do poder familiar são os abusos físicos, psicológicos ou sexuais. A literatura vêm demonstrando coerentemente que esses três tipos de abuso estão correlacionados com o desenvolvimento de comportamentos anti-sociais (Gomide, 2003). Estudos com crianças e adolescentes infratores, agressivos ou usuários de drogas têm enfatizado a alta correlação com vários níveis de abuso (Patterson, Reid, \& Dishion, 1992, Carvalho, 2003, Bahls, 2002, Simons, Wu, Lin, Gordon \& Conger, 2000).

De acordo com Gagno (2002), a adoção é a melhor solução para garantir às crianças abandonadas o direito à convivência familiar, porém não é uma boa alternativa para crianças cujas famílias sofrem com a pobreza, visto que é função da sociedade e do Estado proteger essas crianças e apoiar suas famílias.

Embora a adoção internacional se configure como uma alternativa para o encaminhamento de crianças mais velhas, negras e portadoras de deficiência, como vem sendo defendida pelos serviços de adoção ligados ao Poder Judiciário, deve-se ressaltar que, quando se valoriza a adoção por casais estrangeiros, nomeandoos como "notáveis", maduros, conscientes, capazes de realizarem adoções que os brasileiros não estão dispostos a fazer, deprecia-se a capacidade e a sensibilidade de casais adotivos brasileiros. Essa questão pode estar refletindo, como afirma Santos Filho(2002), a ausência de programas brasileiros que sensibilizem, orientem e acompanhem os casais brasileiros para realizarem esse tipo de adoção, programas esses que provavelmente são realizados no exterior, pois lá não existem crianças brancas e recém-nascidas para serem adotadas, como ainda existem no Brasil. 


\section{Objetivo do Estudo}

O objetivo deste estudo de caso foi o de examinar a documentação e as relações familiares de uma criança abrigada por maus tratos, há três anos sem visita dos pais, tendo em vista as possibilidades de instauração de um processo de extinção do poder familiar.

\section{Método}

\section{Estudo de caso}

Esta pesquisa caracterizou-se por ser um estudo de caso de um menino de três anos e 9 meses de idade, residente em uma instituição-abrigo, internado desde 09/12/1998 por maus tratos e negligência dos pais. A criança foi selecionada dentre outras 12 crianças que tinham pais e não recebiam visitas há mais de um ano e meio.

\begin{abstract}
Abrigo
O abrigo possuía uma infra-estrutura suficiente para atender 40 crianças de um mês a quatro anos de idade. Tinha 18 funcionários, incluindo profissionais responsáveis pela limpeza, cozinha, higiene, recreação, educadoras, além de uma diretora e de uma diretoria social que arrecadava verbas para a manutenção do abrigo e cuidava para que as necessidades médicas, de alimentação, de vestuário, de recreação e de escolarização das crianças fossem atendidas.
\end{abstract}

\section{Instrumentos}

Todos os documentos disponíveis na instituição sobre a criança foram analisados, a saber: (a) relatório da equipe do SOS Criança, indicando que ela deveria ser afastada da família e que os genitores receberiam orientação dos técnicos do Serviço de Orientação Familiar do Programa SOS Criança, (b) formulário de abrigamento, onde constavam as fraturas encontradas na criança por ocasião no internamento no hospital, (c) relatório de avaliação neurológica, com diagnóstico de espancamento e atraso no desenvolvimento motor, cognitivo, fala e linguagem da criança, (d) cartas da instituição, assinadas pela diretora, informando ao Conselho Tutelar que a criança não recebia visitas há um ano e dois meses (15/02/2000), há um ano e 6 meses (02/06/2000)e há um ano e onze meses (16/ $11 / 2000)$.

\section{Entrevistas}

Foram realizadas várias entrevistas para obtenção de dados sobre a criança: (a) com as atendentes e diretora da instituição, (b) com a mãe da criança, (c) com a tia da criança, (d) com o pai da criança, apenas (duas vezes).

\section{Observação de comportamento}

Foram realizadas três observações cursivas do comportamento da criança, na instituição, com duração de aproximadamente duas horas cada: (1) durante o café da manhã e na sala de recreação, (2) na sala de recreação e (3) quando a mãe e irmãos vieram à instituição visitar a criança.

\section{Procedimento}

O primeiro passo foi a análise dos documentos existentes na instituição. Em seguida, foram feitas as entrevistas com as atendentes e diretora e realizou-se a primeira observação de comportamento da criança na instituição. Na seqüência, a mãe da criança foi entrevistada e depois convidada a visitar o filho na instituição. As pesquisadoras foram até à casa dos pais buscar a mãe para levá-la à visitação. No dia da visita, foi realizada a segunda obsenvação. A tia da criança, irmã paterna, foi entrevistada para obtenção de informações sobre as condições de guarda da família da criança. O pai foi entrevistado duas vezes para que se posicionasse a respeito da extinção do poder familiar.

\section{Resultados e Discussão}

Esta pesquisa caracterizou-se por ser um estudo de caso de extinção do poder familiar. Pretendeu-se avaliar os possíveis caminhos a serem trilhados diante de um caso de criança institucionalizada por um período superior a um ano e meio sem visitas parentais.

Este estudo começou com a análise da documentação existente na instituição. Toda essa documentação foi esclarecedora em dois sentidos. Primeiramente, os relatórios médicos confirmavam que a criança sofreu abusos físicos e, por esta razão, havia sido retirada de casa. Em segundo lugar, os documentos demonstravam que ela estava abrigada desde 9/12/98 e jamais havia recebido uma visita; portanto, quando o trabalho foi iniciado, em 16/08/2001, a criança estava há exatamente dois anos e oito meses sem contato com os pais.

As entrevistas com as atendentes, a diretora e a observação de comportamento da criança realizada em horário do café da manhã revelaram dados similares. A criança apresentava boa comunicação com as demais crianças e atendentes, brincava livremente, porém não se aproximava das pesquisadoras quando chamada, como faziam as demais crianças da instituição, que vinham logo pulando no colo dos visitantes. As atendentes declararam que ele era "tímido", que não era agressivo com elas, que às vezes batia a cabeça na parede e já havia mordido outras crianças. A diretora informou que esses comportamentos agressivos eram mais freqüentes anteriormente e à noite. Na ocasião da primeira observação, a criança manteve-se distante das pesquisadoras. Já na segunda observação, brincou, riu e conversou com as pesquisadoras no início e depois se afastou novamente, ficando distante.

As entrevistas com os pais foram feitas em casa e visavam a verificar o seu interesse em receber a criança de 
volta. Inicialmente, a mãe manifestou interesse em visitar o filho, mas disse não saber onde era a instituição, não ter dinheiro para ir visitá-lo e ainda, que seu marido não permitia que ela fosse. A equipe verificou que havia mais dois filhos na casa, um mais velho e uma mais nova. A mãe, espontaneamente, começou a dizer que os filhos nunca haviam apanhado e que o juizado tirou um de seus filhos, que a assistente social do Conselho Tutelar a havia ameaçado de tirar o outro filho caso ela fosse buscar o que estava abrigado. O pai disse que estava revoltado e que se vingaria.

As pesquisadoras foram buscar a mãe em casa, quinze dias após a primeira entrevista, com o intuito de realizar a visita ao filho abrigado. O pai negou-se a ir, estava bêbado e descontrolado. Disse que queria matar a conselheira tutelar: "Quem tirou meu filho de mim é que deveria trazer de volta". A pesquisadora respondeu que estavam apenas levando a mãe para ver o filho na instituição. O pai entrou em casa e a mãe no carro das pesquisadoras com os dois filhos. O cunhado, que morava ao lado, foi até o carro e informou que "aquele homem era sem futuro, que a criança ficaria melhor na instituição do que em casa".

Durante o trajeto, a mãe contou que o filho mais velho era muito agressivo, que o marido não permitia que ela saísse de casa desacompanhada da cunhada ou da sogra, que era muito ciumento, agressivo e irritado. Afirmou que ele era alcóolatra e usava drogas, e que precisava arrumar emprego, pois tudo o que ganhava como pedreiro gastava em bebidas e drogas. Afirmou que ele era agressivo com ela e com a própria mãe.

$\mathrm{Na}$ instituição, a criança foi apresentada à mãe e aos irmãos e chorou. Em seguida, começou a bater a cabeça nas paredes, batia os pés e fechava os olhos. Não se afastou da mãe. Após uma hora de visita, ele começou a sorrir, a conversar, a sentir-se mais à vontade. O irmão mais velho chutou a irmãzinha e uma das pesquisadoras. A mãe justificou o comportamento do filho dizendo que ele agia assim porque já presenciara vários espancamentos do pai em relação a ela, incluindo uma tentativa de enforcamento. A mãe mostrou-se gentil e carinhosa com o filho abrigado.

Dez dias depois dessa visita, as pesquisadoras entraram em contato telefônico com a mãe para saber qual o encaminhamento a ser dado. Ela respondeu que havia apanhado do marido por ter ido visitar o filho e por ciúmes do pai de uma das pesquisadoras, que estava dirigindo o carro que as levou à instituição. Foi solicitado à mãe que viesse às dependências do Centro de Psicologia Aplicada da UFPR, junto com a cunhada, para que conversássemos sobre suas intenções em relação ao filho abrigado e aos possíveis encaminhamentos. A mãe não compareceu ao CPA e, em telefonema subseqüente, a cunhada informou que a mãe estava disposta a abrir mão do poder familiar, pois a criança somente sofreria se voltasse para casa.

A equipe de pesquisadoras foi informada, um mês depois, que a mãe havia abandonado a casa levando a filha mais nova e deixando o mais velho com a avó. A cunhada informou que a mãe batia no filho mais velho e tinha sido vista abusando sexualmente da filha mais nova, masturbando-a no quintal de casa. A cunhada confirmou que o pai batia tanto nos filhos como na mulher, mas somente quando bebia ou usava drogas.

Um mês depois, o pai resolveu assinar o documento permitindo que se encaminhasse a solicitação de extinção do poder familiar, tendo assinado também uma procuração instituindo advogada para dar prosseguimento ao processo.

O processo de extinção do poder familiar foi aberto em Junho de 2001 e foi analisado pelo Cartório da Primeira Vara da Infância e Juventude. A extinção do poder familiar ocorreu em 15 de abril de 2003. Nesse ínterim, a criança foi transferida da instituição para uma casa-lar. Isso ocorreu porque a criança completou quatro anos de idade e não mais poderia permanecer naquele abrigo, que somente aceitava crianças até quatro anos. As pesquisadoras foram visitá-lo. Estava morando com mais sete crianças, incluindo duas meninas que foram transferidas com ele. A criança continua tendo o comportamento de bater a cabeça na parede quando fica aborrecido e tem muito medo de fogos de artifício e trovões. Tem um bom relacionamento com as outras crianças da casa e brincou com as pesquisadoras durante a observação, não demonstrando mais o comportamento de esquiva.

\section{Considerações Finais}

A situação da criança aqui analisada é similar à de milhares de outras crianças abrigadas em nosso país. O Judiciário coloca-as sob a sua guarda, protegendoas temporariamente do abandono, dos maus-tratos, da negligência, porém não thes dá uma nova oportunidade de reintegração social através de uma adoção, extinguindo o poder familiar daqueles que não mais estão interessados em acompanhar o destino dos filhos. Muitos casais, em fila de espera para adoção, sequer cogitam a possibilidade de adotar essas crianças, pois, por não estarem nas listas de crianças disponíveis para adoção, não são identificadas como possíveis filhos adotivos. As crianças perdem suas chances de recomeçarem uma nova vida e os pais adotivos a de Ihes oferecerem o afeto que elas tanto necessitam para sobreviver aos traumas de que foram vítimas nessa curta fase de suas vidas.

Essa discussão não pode passar ao largo da constatação de que inexistem programas eficazes para apoio às famílias desassistidas, de risco, que permanecem enfrentando com seus parcos recursos financeiros e psicológicos os desafios de viver em uma sociedade desprovida de políticas públicas de saúde e de educação mínimas. A essas famílias, pouco resta a não ser ver seus filhos levados pelos serviços de proteção à criança, para serem colocados em abrigos permanentes. 
Independentemente de a principal motivação para adoção ainda hoje ser a esterilidade dos pais, existem evidentes movimentos sociais a favor da adoção interracial e de crianças mais velhas. Esse início de conscientização, tanto social como jurídica, tem permitido a abertura de um debate sobre a real situação das crianças institucionalizadas que poderiam ser encaminhadas para adoção através de processos de extinção do poder familiar. A cultura de proteção à criança dos séculos passados visava a guardar as crianças e adolescentes em instituições até a maioridade. A atual diretriz visa a encontrar famílias que resgatem essas crianças do abandono e lhes dêem moradia digna. Para que isso seja viável, é preciso que a Justiça exerça o seu papel, liberando essas crianças para a adoção e é preciso que os meios de comunicação sensibilizem os casais que anseiam por filhos para que deitem seu olhar amoroso para essa parcela dos filhos de Deus que espera por um lar.
A defesa feita neste artigo da extinção do pátrio poder para este caso não se contrapõe à defesa de políticas de apoio às famílias de risco. Trata-se, por um lado, da identificação de riscos familiares que inviabilizariam o desenvolvimento saudável da criança e, por outro lado, da possibilidade de, através da extinção do poder familiar, dar à criança abrigada uma oportunidade de reintegração familiar. Esse procedimento poderá evitar que a criança se torne um filho dos internatos brasileiros. Verifica-se que, tanto nas equipes dos abrigos como nas equipes dos órgãos governamentais, a identificação das possibilidades de retorno familiar ou, por outro lado, de extinção do poder familiar não é feita de forma qualificada. As decisões são tomadas sob pressão do Judiciário para desinternamento, por falta de vagas ou para tentar atender ao princípio do ECA que prioriza o retorno familiar.

A criança deste estudo de caso está aguardando seus futuros pais adotivos.
BALHS, F. M. R. C. Análise de Auto-relatos de Adolescentes que Buscaram Tratamento por Uso de Substâncias Psicoativas". Dissertação de Mestrado, Universidade Federal do Paraná, 2002.

BARBOZA, H. H. O Princípio do Melhor Interesse da Criança e do Adolescente. In R. C. Pereira (org.). A Família na Travessia do Milênio: Anais do II Congresso Brasileiro de Direito de Família. IBDFAM e OAB-MG, Belo Horizonte, 2000.

BOWLBY, J. Apego. São Paulo: Martins Fontes, 1984 a . Separação: vol. 2 da Trilogia Apego e Perda. São Paulo: Martins Fontes, 1984b.Cuidados Maternos e Saúde Mental. São Paulo: Martins Fontes, 1988.

CARVAlHo, M.N. Efeitos das Práticas Educativas Parentais Sobre o Comportamento Infrator de Adolescentes". Dissertação de Mestrado, Universidade Federal do Paraná, 2003.

CÓDIGO CIVIL. Lei no. 10.406, de 10-01-2002, acompanhada de legislação complementar, súmulas e índices. São Paulo: Editora Saraiva.

CONSTITUIÇÃO FEDERAL (1988). São Paulo: Editora Saraiva, 1991.

DODGE, K.A., PETIT, G. S. \& BATTES, J. E. (1994). Socialization Mediators of the Relation Between Socioeconomic Status and Child Conduct Problems. Child Development, 65, pp. 649-665.]

EBRAHIM, S.G. Adoção Tardia: Altruísmo, Maturidade e Estabilidade Emocional. Dissertação de mestrado, Universidade Federal da Paraíba, 1999.

ESTATUTO DACRIANÇAEDOADOLESCENTE(Lei 8.069, de 13 de Julho de 1990). São Paulo: EditoraSaraiva, 1995. FERRÃO, (2000).

GAGNO, A. P.O Percurso da Adoção na Imprensa Brasileira. Dissertação de Mestrado, Universidade Federal do Paraná, 2002.

GOMIDE, PI.C. (2003). Estilos Parentaise Comportamento Anti-social. In A. Del Prette e Z. Del Prette (orgs). Habilidades Sociais, Desenvolvimento eAprendizagem: Questões Conceituais, Avaliaçãoe Intervenção. Campinas: Alínea. No prelo.

GUIMARÃES, M. Igualdade. Curitiba:v.07, n.25. pp. 156-165out./dez. 1999.

PATTERSON, G.; REID, J. \& DISHION, T. Antisocial Boys. EUA: Castalia PublishingCompany, 1992.

PEREIRA, T.S. O Princípio do Melhor Interesse da Criança: da Teoria à Prática. In R. C. PereiraAfamília na travessia do Milênio:Anais do IICongresso Brasileiro de Direito de Família. IBDFAM e OAB-MG, Belo Horizonte, 2000.

SANTOS FILHO, J. Aopção dosvencidosou los massacres de la ciudadania. In V.R. Müller \& A.J. Morelli (org), Crianças e Adolescentes: a Arte de Sobreviver. Maringá: Editora da Universidade Estadual de Maringá, PR, 2002.

SIMONS, R.L., WU, C., LIN K., GORDONn, L. \& CONGER, R. ACrosscultural Examination of the Link Between Corporal Punishment and Adolescent Antisocial Behavior. Criminology, 38, 2000, pp. 47-80.

WEBER, L. N. D. \& KOSSOBUDZKI, L. H. M. Filhos da Solidão: Institucionalização, Abandono e Adoção. Secretaria de Estado da Cultura do Paraná. Imprensa Oficial do Estado do Paraná, 1996.

WEBER, L. N. D. Laços de Ternura: Pesquisa e Histórias de Adoção. Curitiba: Editora Juruá, 1998. 